\title{
Article \\ On the Use of Chromium Coating for Inner-Side Fuel Cladding Protection: Thickness Identification Based on Fission Fragments Implantation and Damage Profile
}

\author{
Rofida Hamad Khlifa *, Nicolay N. Nikitenkov and Viktor N. Kudiiarov \\ Department of Experimental Physics, School of Nuclear Technology Engineering, \\ National Research Tomsk Polytechnic University, Lenin Avenue 30, 634050 Tomsk, Russia; \\ nikitenkov@tpu.ru (N.N.N.); kudiyarov@tpu.ru (V.N.K.) \\ * Correspondence: rofida@tpu.ru
}

check for updates

Citation: Khlifa, R.H.; Nikitenkov, N.N.; Kudiiarov, V.N. On the Use of Chromium Coating for Inner-Side Fuel Cladding Protection: Thickness Identification Based on Fission Fragments Implantation and Damage Profile. Coatings 2021, 11, 710 . https://doi.org/10.3390/ coatings11060710

Academic Editors: Rubén González and Cecilia Bartuli

Received: 20 April 2021

Accepted: 8 June 2021

Published: 12 June 2021

Publisher's Note: MDPI stays neutral with regard to jurisdictional claims in published maps and institutional affiliations.

Copyright: (c) 2021 by the authors. Licensee MDPI, Basel, Switzerland. This article is an open access article distributed under the terms and conditions of the Creative Commons Attribution (CC BY) license (https:// creativecommons.org/licenses/by/ $4.0 /)$.

\begin{abstract}
Inner-side coatings have been proposed as a complementary solution within the accident tolerant fuel (ATF) framework, to provide enhanced protection for the nuclear fuel cladding. Unlike external surface, the degradation of irradiated internal cladding surface has not been studied extensively. Fission fragments produced during the fission of nuclear fuel is one of the key players in this degradation. This study aimed to estimate the minimum thickness of the thin chromium film, required to protect the inner side of the nuclear fuel cladding. The approach used is based on a set of calculations, of Ion ranges and damage profiles, for a group fission fragments, using the TRIM code. The calculation results were verified by comparison with the experimental data associated with the phenomena of the inner cladding degradation of thermo-releasing elements. The recommended minimum thickness for such a film was found to be 9 microns. Calculations also showed that chromium metal has a greater stopping power compared to the zirconium-based alloy E110, which indicates an increased ability of chromium to withstand exposure to energetic fission fragments during reactor operation.
\end{abstract}

Keywords: fuel cladding; advanced fuel cladding; protective coatings; chromium; fission fragments

\section{Introduction}

As a response to the design flaws exposed by Fukushima Nuclear Accident in 2011, a global shift has been occurred in nuclear fuel research, towards a fuel with specific ability to tolerate accidents. The concept of accident-tolerant fuel (ATF) has emerged as a unique fuel design expected to improve the safety of nuclear reactors. The underlying principle behind the ATF concept is to enable a reactor core to remain intact for a rather long time without the need for swift operator interventions in cases of severe events, when the external cooling supply is lost. Among the core tasks of ATF, is the design of cladding materials with outstanding performance [1].

Numerous cladding concepts have been proposed, however; those involving a complete replacement for the zirconium based alloys have a greater uncertainty and would represent a relatively long-term solutions. In contrast, using protective surface coatings with the existing zirconium alloys is expected to provide improved performance, without introducing significant changes into the current uranium dioxide - zirconium $\left(\mathrm{UO}_{2}-\mathrm{Zr}\right)$ fuel system design. This would represent a more conservative, short-term technical route with favorable application prospects [1].

Due to its high melting point, intrinsic ductility and similar thermal expansion coefficient to that of zirconium $(\mathrm{Zr})[1,2]$, Metallic chromium $(\mathrm{Cr})$ has attracted attention as a potential coating material on zirconium alloys, to limit external cladding corrosion in normal operating conditions, and to delay zirconium oxidation during severe accidents events. An extensive research has been triggered worldwide to investigate the feasibility of 
this solution. Different deposition technologies haves been used, such as: physical vapor deposition (PVD) by CEA (France), vacuum arc ion-plasma technology in Russia, 3D laser technology, cold spraying and arc ion plating in Korea [2]. This research showed that applying metallic chromium thin film significantly improved corrosion resistance in Zircaloy claddings $[3,4]$. Coated samples demonstrated negligible reduction in residual strength and ductility, improved ballooning and rapture resistance, and reduced hydrogen pickup, compared with uncoated Zircaloy claddings in light water reactors (LWRs) environment. This further enhances life extension and burnup efficiency of nuclear fuel [1], however; research focused mainly on depositing chromium coating on the external surface of cladding. A realistic scenario that steam from the outer environment enters the cladding tube, through a rupture after ballooning and bursts, under loss of coolant accident (LOCA) conditions, or through cracks arise as a consequence to stress corrosion cracking (SCC) phenomenon, led by the projected stresses on the deformed fuel and the presence of accumulated fission products (FPs) in the pellet-clad interface (PCI). Steam leaked into the unprotected inner surface of cladding can cause a rapid oxidation and secondary hydrogenation, eventually complicating the accident scenario further [1].

Unlike external surface, the oxidation and degradation of the irradiated internal surface of fuel cladding have not been studied extensively. The presence of fission fragments produced by the fission of nuclear fuel has been closely linked to this degradation. Indeed, the contribution of FPs to the damage of fuel cladding materials has been known for a long time. During a reactor's operation, the dose rate of FPs is approximately 12.5 times to that of neutron and gamma radiation [5]. Phenomena such as corrosion, SCC, embrittlement and reduction of ductility [6,7] has been closely linked to the aggressive environment caused by the presence of FPs and their migration to the internal surface of the cladding.

To provide protection and limit the damage on the internal side of fuel cladding, applying an inner thin film coating have been proposed [8]. In fact; this concept is not new, internal surface coatings were proposed in the 1970s as a solution for the problem of SCC in power reactors. A graphite film successfully applied in CANDU reactor claddings due to its relatively short length (about $0.5 \mathrm{~m}$ ), however; obstacles such as the practicality of applying thin films on the internal wall of a $4.5 \mathrm{~m}$ long tube has hindered the wide implementation of this solution [9]. Recently; the advancements in thin film technologies brought this topic into the front as a complementary solution within the ATF framework $[8,10,11]$, nevertheless; there are still several process parameters which need to optimized such as coating's structure, defects, and thickness.

As an attempt to bring some new comprehension elements that would contribute in optimizing surface coating process parameters, this study aims to identify the minimum Chromium thin film thickness, which is able to provide sufficient protection for the internal surface of fuel cladding. The approach used, is based on identifying the potential extension of internal damage, through set of calculations, of the maximum implantation depths and damage profiles for a group of FPs, mostly known to have major contributions in the degradation of the internal surface of fuel cladding. Based on this calculations; a minimum thin film thickness is selected. This film is expected to offer a substantial degree of protection, by containing and limit the effects of FPs migrating to fuel cladding walls. Furthermore, this established approach could be beneficial in indentifying the minimum inner-surface thin film thickness, for various coating materials proposed within the ATF framework, based on the material being investigated.

\section{Methodology and Input Parameters}

\subsection{Fission Products}

Ion ranges and displacement damage was simulated for a group of FPs using TRIM2008, to identify the maximum implantation ranges and damage profiles for this FPs inside the internal surface of fuel cladding. The group of FPs included: noble metal phase particles: technetium $(\mathrm{Tc})$, ruthenium $(\mathrm{Ru})$, molybdenum $(\mathrm{Mo})$, rhodium $(\mathrm{Rh})$ and palladium $(\mathrm{Pd})$, in addition to the volatile products iodine (I), and cesium (Cs). The Zr-based alloy E110 
(composition is given in Table 1), widely utilized as fuel cladding material in Russian WWER reactors, was used as a substrate in this simulation. Based on the calculated ranges and damage; an appropriate thin film thickness of metalic $\mathrm{Cr}$ was designated.

Table 1. Average chemical composition of E110 Alloy.

\begin{tabular}{cc}
\hline Element & Content (wt. $\%)$ \\
\hline Niobium $(\mathrm{Nb})$ & 1.00 \\
\hline Zirconuim $(\mathrm{Zr})$ & balance \\
\hline
\end{tabular}

Based on the experimental measurements, fission fragments are produced with different energies and different yields [12,13]. The more energetic the particle, the more it can travel inside the material. As a conservative approach, the maximum expected energies, which is normally corresponds to very small yields [12], is used in the simulations performed in this study, this will contribute to a more precise selection of the minimum thickness of thin film.

The simulated FPs is characterized by the relatively high production yield during nuclear fuel fission process. Traces of these products have been detected inside the fuel cladding by many researchers, and a close linkage were firmly established between their presence and many cladding degradation phenomena, such as the internal corrosion, the SCC, the internal cladding surface hardening, embrittlement and reduction of ductility. Experimental observations showed that the noble metal phase particles exist as polycrystalline metallic agglomerates [14] inside the internal cladding wall, this marks these products as key players in cracks initiation [15], due to the consequent hardening caused by their presence in this form. Once cracks is initiated, Corrosive volatile species; such as iodine and cesium find their way through the cracks, react with zirconium, and cause further corrosion, eventually extending this cracks through the cladding walls.

Different initial numbers of incident ions were simulated, e.g., 4000, 10,000, 20,000, 30,000 , etc. The simulations showed that the range of this ions and the damage seem to be saturated (cascade saturation) after a certain number of ions, as the calculated ranges and damage gave the same implantation depths, and almost the same damage for the different number of incident ions. The number of incident ions for the simulated group of FPs is taken to be 4000 ions in this study.

\subsection{SRIM Software}

Stopping and Range of Ions in Matter (SRIM) is a software package developed by Ziegler (Rockville, MD, USA), based on the binary collision approximation (BCA) method [16]. It has the ability to estimate many features related to the transport of ions in matter $[13,16,17]$. The BCA is a Monte Carlo method designed to calculate deposition profiles in materials exposed to energetic ion beams. The underlying assumption is that an energetic particle collides with a target atoms will lose its kinetic energy in this collosions, elasticly with atoms, and inelasticly with electrons, target atoms may receive enough energy to undergo additional collisions.

Transport of Ions in Matter (TRIM) is one of SRIM modules, widely used in ion beam implantation and processing calculations [17], it accepts and handles complex targets (compound materials) with many layers up to eight. TRIM offers different options to estimate the damage in a target, based on the type and details of outputs required. The full damage cascade (F-C) mode follows each recoiling atom (primary, secondary, etc), until its energy drops below threshold displacement energy $\left(E_{d}\right)$ of any target atom, therefore, all collisions to the target is considered and analyzed. The quick calculation of damage (K-P) mode follows only the path of incidence ions, it could be used when little attention is needed about the details of the target damage or the surface sputtering. The calculated damage with this option represents a quick statistical estimate based on the Kinchin-Pease formalism "K-P" [18]. Both F-C and K-P options give the same ion ranges in a specific 
target [12], however; the first method is time consuming when compared with the K-P method since the progression of the cascade is not followed in the later. As we are mainly interested in the range of ions and the depth of the damage rather than the damage details, the second method have been adopted in this study.

K-P theory is originally proposed by Kinchin and Pease, extended by Lindhard, and later by Norgett, Robinson and Torrens (NRT)] [16]. In this theory, the defect producing energy $E_{\gamma}$, is obtained from the transferred energy $T$ of the recoil by taking into account electronic losses [16]:

$$
\mathrm{E}_{\mathrm{v}}=\frac{\mathrm{T}}{1+\mathrm{K}_{\mathrm{d}} \mathrm{g}\left(\varepsilon_{\mathrm{d}}\right)}
$$

where the electronic losses are governed by:

$$
\mathrm{K}_{\mathrm{d}}=-0.1334 \mathrm{Z}_{2}^{\frac{2}{3}} \mathrm{M}_{2}^{-1 / 2}
$$

where $Z_{2}$ and $M_{2}$ are the atomic number and atomic mass for the target atoms and:

$$
\mathrm{g}\left(\varepsilon_{\mathrm{d}}\right)=\varepsilon_{\mathrm{d}}+0.40244 \varepsilon_{\mathrm{d}}^{3 / 4}+3.4008 \varepsilon_{\mathrm{d}}^{1 / 6}
$$

where $\varepsilon_{\mathrm{d}}$ is a reduced energy given by:

$$
\varepsilon_{\mathrm{d}}=0.01014 \mathrm{Z}_{2}^{7 / 3} \mathrm{~T}
$$

From the transferred energy to target atoms, $E_{v}$, the number of displacements, $v$, is calculated by the modified Kinchin-Pease model:

$$
\begin{aligned}
& v=1, \text { if } E_{d}<E_{v}<2.5 E_{d} \\
& v=\frac{0.8 E_{v}}{2 E_{d}} \text { if } E_{v}>2.5 E_{d}
\end{aligned}
$$

TRIM inputs used in this study are given in Table 2. The displacement energy is the energy required by a recoil atom, to overcome the lattice forces, and to move more than one atomic spacing away from its original site. The lattice binding energy is the energy that every target atom loses, when it leaves its lattice site and recoils in the target, and the Surface binding energy is the energy that target atoms must overcome to leave the surface of the target.

Table 2. Input parameters for TRIM calculations.

\begin{tabular}{ccccccc}
\hline Element & $\begin{array}{c}\text { Atomic } \\
\text { Number }\end{array}$ & Weight (amu) & Fraction (\%) & $\begin{array}{c}\text { Displacement } \\
\text { Energy (eV) }\end{array}$ & $\begin{array}{c}\text { Lattice Binding } \\
\text { Energy (eV) }\end{array}$ & $\begin{array}{c}\text { Surface Binding } \\
\text { Energy (eV) }\end{array}$ \\
\hline $\mathrm{Zr}$ & 40 & 91.22 & 99 & 40 & 3 & 6.33 \\
\hline $\mathrm{Nb}$ & 41 & 92.90 & 1 & 60 & 3 & 7.59 \\
\hline $\mathrm{Cr}(\mathrm{Chromuim})$ & 24 & 51.99 & 100 & 40 & 3 & 4.12 \\
\hline
\end{tabular}

\section{Results and Discussion}

\subsection{Ion Ranges}

Figures 1 and 2 show the calculated ion ranges for the noble metal phase particles: $\mathrm{Tc}, \mathrm{Ru}, \mathrm{Mo}, \mathrm{Rh}$, and $\mathrm{Pd}$, in addition to volatile products iodine and $\mathrm{Cs}$, in the zirconium based alloy E110. This corresponds to the maximum recoil energy for these elements from the fission of uranium $-235\left(\mathrm{U}^{235}\right)$. The fission yield for this group of products, which is expected to reach the inner surface of the fuel cladding with such high recoil energies, is anticipated to be very small. According to calculations made by Rymzhanov et al. [12], in an attempt to estimate the relative yield, energy and flux of fission fragments (from the fission of ${ }^{235} \mathrm{U}$ and plutonium ${ }^{239} \mathrm{Pu}$ ) on the surface of nuclear fuel cladding, using 
the experimental spectra of fission products, this yield is expected to range between $10^{-8}$ to $10^{-9}$. This extremely small yield is probably the reason behind the inability to experimentally detect the physical presence of these products behind certain depths inside fuel cladding in some studies, such as those done in [5,14]. As these particles are being ejected with very high levels of energy, the damage caused was actually recorded in depths higher than that in which their physical presence was confirmed by Lach et al. [5]. Nevertheless, the small and very limited yield may have inhibited the agglomeration of these particles, and thus, impeding their physical detection by some researchers.

As shown in Figures 1 and 2, the depths into which those elements could reach inside the fuel cladding ranges between $\sim 8-10 \mu \mathrm{m}$. This result is fairly consistent with the findings of Hirabayashi et al. [19], in their investigation of the distribution of radionuclides in PWR spent fuel Zircaloy-4 cladding, using a stepwise etching process. According to these findings, more than $98 \%$ of fission products in the cladding exist within a $10 \mu \mathrm{m}$ depth from the inner surface of the cladding. Moreover, the abundance of fission products inside the cladding have shown to follow a gradient distribution with the depth, this could be directly linked to the gradient in yield and energy for fission recoils reaching the inner surface of fuel cladding [12].

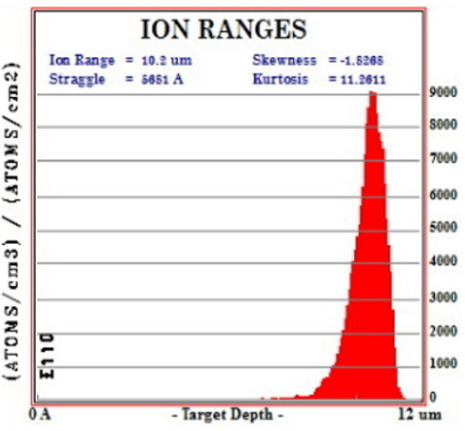

(a)

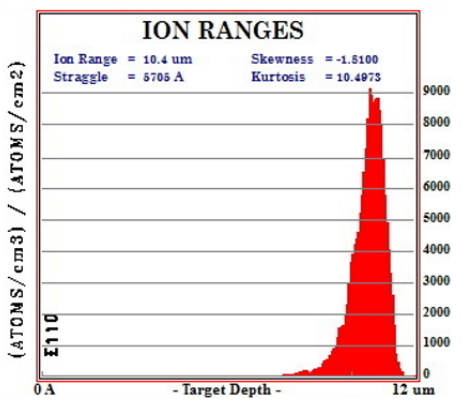

(c)

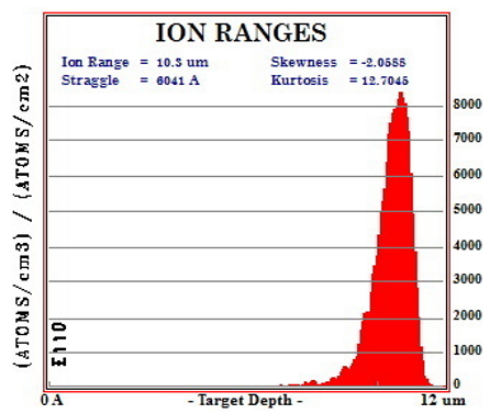

(b)

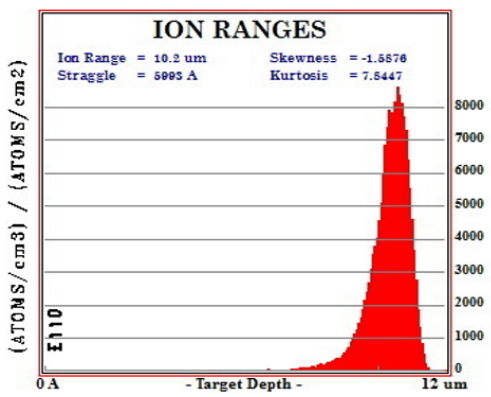

(d)

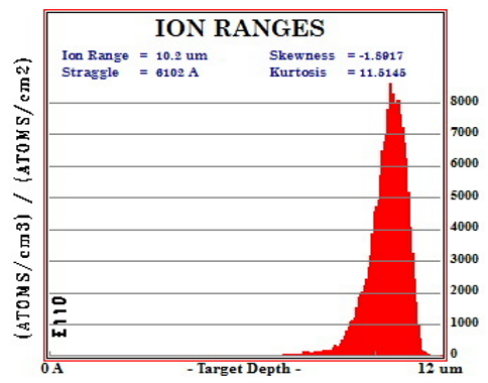

(e)

Figure 1. Ion ranges for the Fission Products (FPs): (a) Technetium (Tc); (b) Ruthenium (Ru); (c) Molybdenum (Mo); (d) Rhodium (Rh); and (e) Palladium (Pd), in E110 alloy, with recoil energy $120 \mathrm{MeV}$, corresponds to the maximum expected releasing energy for these fragments from the fission of Uranium -235 . 


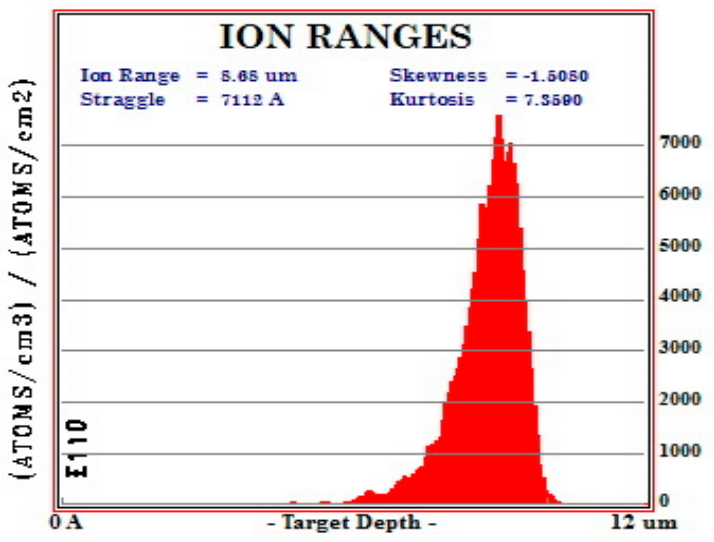

(a)

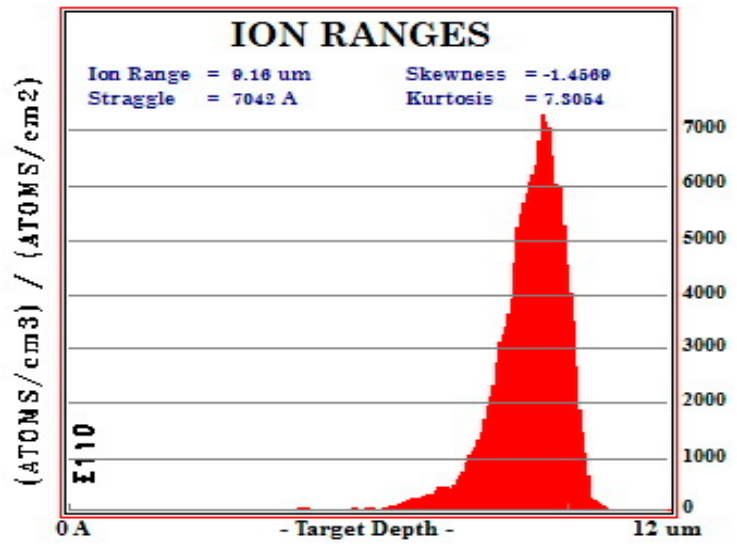

(b)

Figure 2. Ion ranges for the volatile FPs: (a) Iodine (I) with recoil energy $90 \mathrm{MeV}$; and (b) Cesium (Cs) with recoil energy $95 \mathrm{MeV}$, in E110 alloy.

The results obtained in Figures 1 and 2 are also similar to the observations made by Ciszak et al. [20] in their study of the fuel-cladding bonding layer in high burnup fuel for a sample prepared from a Zircaloy-4 cladded fuel rod, and examined using micro- Raman spectroscopy. They demonstrated an implantation gradient of the fission products on the zirconia scale, these FPs implantations ranged from 8 to $10 \mu \mathrm{m}$ in depth inside the zirconia.

The implantation ranges for $\mathrm{Pd}, \mathrm{Ru}$ and $\mathrm{Rh}$ particles with lower recoil energies (produced in a higher yield during the fission process $\sim 5 \times 10^{-4}-10^{-5}$ [12]) was also simulated (Figure 3), to show that these particles would own shorter ranges inside the zirconium based cladding. In this case, since the yield is higher, more atoms will be available to agglomerate and form the polycrystalline particles observed by T.G. Lach et al. [5], in their investigation of the effects of FPs metal particles, on the stability and grain size of the tetragonal phase Zirconium-oxide $\left(\mathrm{ZrO}_{2}\right)$, forms in BWR fuel cladding liner at high burnup. In this study, the authors have detected the presence of solid noble metal particles (Mo, $\mathrm{Tc}, \mathrm{Ru}, \mathrm{Rh}$, and $\mathrm{Pd}$ ) in depths between 5.5-6 $\mu \mathrm{m}$ inside the $\mathrm{ZrO}_{2}$, which coincides with the same depth at which the pure $\mathrm{ZrO}_{2}$ tetragonal phase occurs. Beyond this region of a purely tetragonal phase, they observed a transition region that consists of a combination of both tetragonal and monoclinic phases, but no fission particles was detected. The authors attributed this to the presence of fission recoil radiation at a rate high enough to partially stabilize the tetragonal phase, but too low to accumulate atoms into particles.

The results obtained in Figure 3 also show a good agreement with the study of Clark et al. [14], in which they performed a detailed microscopic analysis for fission products in the cladding. They detected the presence of noble metal phase particles ( $\mathrm{Tc}, \mathrm{Ru}, \mathrm{Mo}, \mathrm{Rh}$ and $\mathrm{Pd}$ ) in a form of agglomerated polycrystalline particles, rather than single crystals form, within the oxidized phase of $\mathrm{Zr}$ liner of spent nuclear fuel. The morphology and size distribution of the noble metal phase particles varied as a function of depth from the $\mathrm{UO}_{2}$ fuel to the $\mathrm{Zr}$-oxide region. Within the first 3-4 $\mu \mathrm{m}$ from the fuel, there were large particles with diameters greater than $100 \mathrm{~nm}$ coexisting with particles that were about 50-70 nm in diameter. As the depth into the $\mathrm{Zr}$-oxide increased up to 5-6 $\mu \mathrm{m}$, the average size of the particles decreased. The findings in [14] again confirm the assumption that FPs follow a gradient distribution in yield and energy, in their migration from the fuel into the inside surface of the cladding, the higher the energy; the lower the yield, and the longer the depth a fission recoil will reach inside the fuel cladding. Within shorter depths, as the yield is higher, more atoms were available to agglomerate and form the large particles observed by the authors in [14], as the depth increased, the yield decreased, therefore the average size of the particles decreased. 


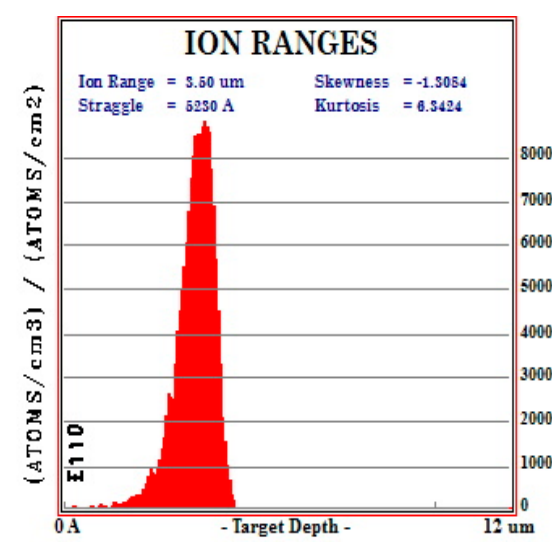

(a)

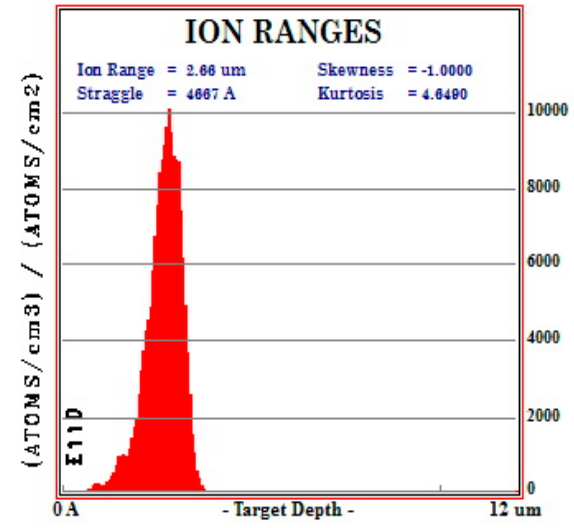

(b)

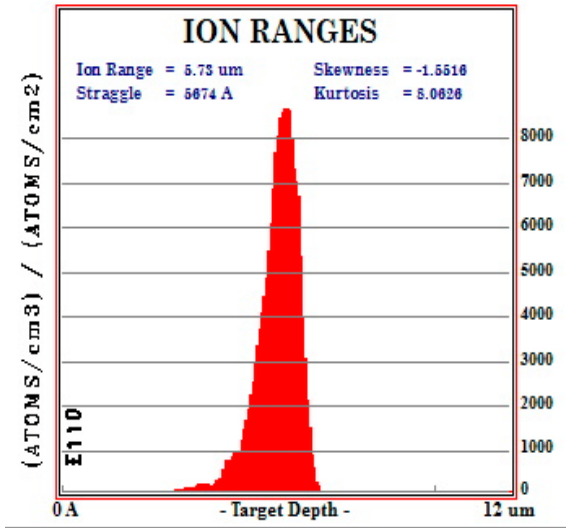

(c)

Figure 3. Ion ranges for: (a) Pd with energy $19 \mathrm{MeV}$; (b) Ru with energy $12 \mathrm{MeV}$; and (c) Rh with energy $45 \mathrm{MeV}$, in E110 Alloy. The maximum implantation depths for this FPs are: $5.5 \mu \mathrm{m}$ for Pd, $2.66 \mu \mathrm{m}$ for Ru, and $5.7 \mu \mathrm{m}$ for Rh respectively.

\subsection{Damage Profiles and Thin Film Thickness}

The maximum damage in E110 alloy, which corresponds to maximum anticipated recoil energies for FPs, was simulated. Based on the implantation and damage ranges, a minimum thin film thickness that would be able to provide sufficient protection for the inner-surface of fuel cladding is selected.

Figure 4 shows the damage caused by $120 \mathrm{MeV}$ Tc in E110, calculated by TRIM using Kinchin-Pease approximation. The damage extends to a depth of over $10 \mu \mathrm{m}$ inside the cladding. A total damage of 27,162 vacancies per ion is produced in the alloy. A thin film of $\mathrm{Cr}$ of about $9 \mu \mathrm{m}$ was applied and a simulation for the damage was done again. It has been found that this thickness will be suitable to provide protection for the cladding material, as it efficiently contained the damage of this energetic particle (Figure 5). Its worth mentioning that the total damage created by the same ion, with same energy, is much less when applying a chromium thin film as it is estimated to be 22,725 vacancies /ion. Since TRIM assumes that all targets are amorphous, this is cannot be explained in the context of crystallographic differences, however; this could be arising from the differences in atomic and electronic structures.

\section{Total Displacements}

Total Displacements $=27162 /$ Ion

Total Vacancies $=27162 /$ Ion

Replacement Collisions $=0 /$ Ion

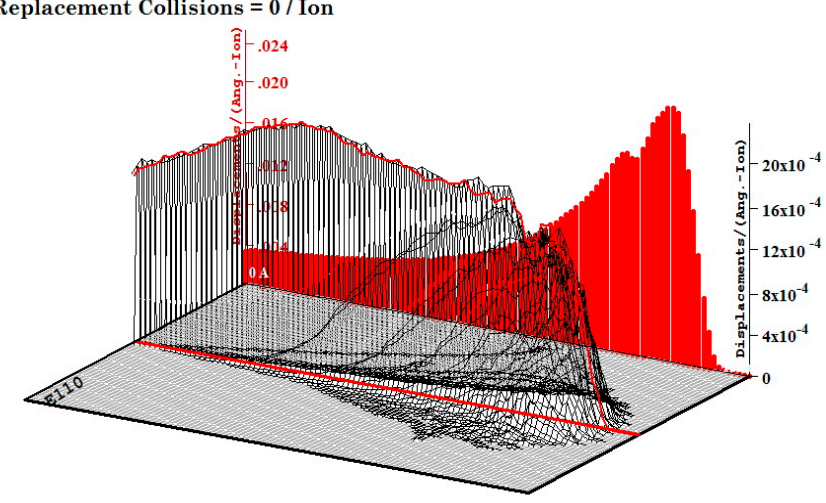

Plot Window goes from $0 \mathrm{~A}$ to $12 \mathrm{um}$; cell width $=1200 \mathrm{~A}$

Figure 4. Damage caused by $120 \mathrm{MeV}$ Tc in E110 alloy. 


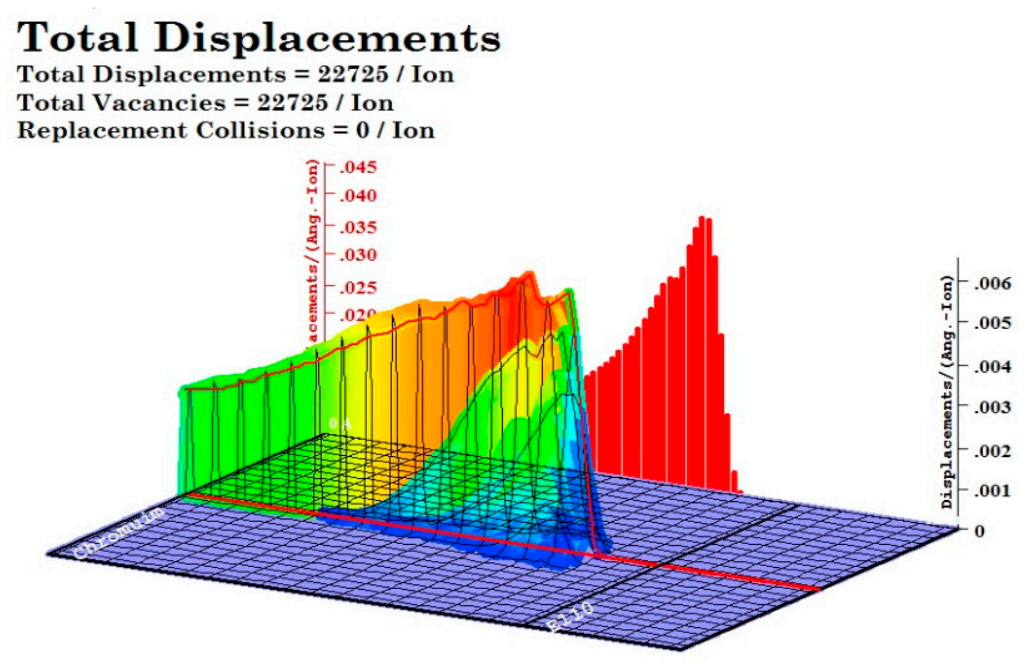

Plot Window goes from $0 \mathrm{~A}$ to $12 \mathrm{um}$; cell width $=1200 \mathrm{~A}$

Figure 5. Damage caused by $120 \mathrm{MeV}$ Tc in E110 alloy, coated with $9 \mu \mathrm{m}$ thin film of Chromium (Cr).

It could be noticed that using $8 \mu \mathrm{m}$ film of $\mathrm{Cr}$ would possibly contain the damage caused by the energetic Tc recoil, nevertheless; the range of Tc in metallic $\mathrm{Cr}$ is estimated to be $7.29 \mu \mathrm{m}$ in this case (Figure 6). Thus, the damage may extend to the cladding/chromium coating interface region as shown in Figure 7, which in turn would possibly affect coating adhesion, as defects and vacancies will be existing near the interface region. It's also obvious from Figure 7 that the concentration of vacancies is the highest near the interface region; this may lead to creation of voids, as a result to the coexistence of large number of vacancies, which in turn would compromise the cohesion of the coating.

\section{Ion Distribution}

Ion Range $=7.29$ um Skewness $=-1.936$

Straggle $=3181 \mathrm{~A} \quad$ Kurtosis $=11.732$

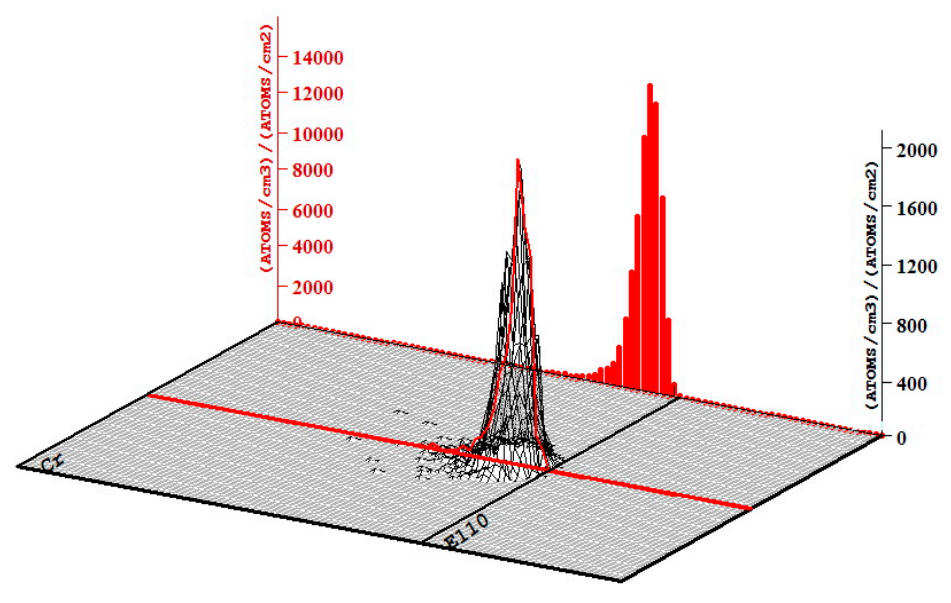

Plot Window goes from $0 \mathrm{~A}$ to $12 \mathrm{um}$; cell width $=1200 \mathrm{~A}$

Figure 6. Ion range for $120 \mathrm{MeV}$ Tc in E110 alloy, coated with $8 \mu \mathrm{m} \mathrm{Cr}$ thin film. 


\section{Total Displacements}

Total Displacements $=22725 /$ Ion

Total Vacancies $=22725 /$ Ion

Replacement Collisions $=0 /$ Ion

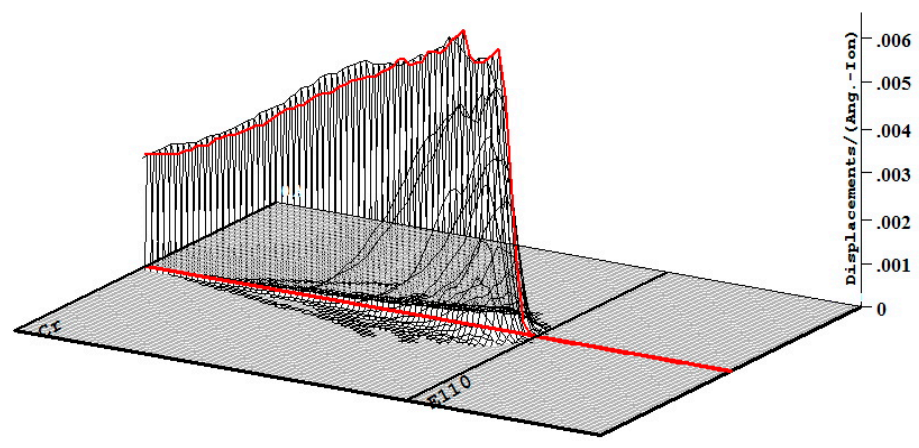

Plot Window goes from $0 \mathrm{~A}$ to $12 \mathrm{um}$; cell width $=1200 \mathrm{~A}$

Figure 7. Damage caused by $120 \mathrm{MeV}$ Tc in E110 alloy, coated with $8 \mu \mathrm{m}$ thin film of Cr.

Figure 8 shows the calculated maximum damage caused by ruthenium $(\mathrm{Ru})$ fission product in the fuel cladding (E110). This corresponds to recoil energy of about $120 \mathrm{MeV}$. The calculations show that a thin film of $\mathrm{Cr}$ of about $9 \mu \mathrm{m}$ will be able to protect the inner surface of fuel cladding from the effect of this FP (Figure 9). The difference in the calculated displacement damage could also be observed for this case. Note that no replacement collisions have been registered, this is because; replacement collisions occur when the incident ions and the target have the same atomic numbers, and the incident ion loses it energy to a target atom, the target atom gain enough energy to leave its lattice site, while the incident ion remains with no energy to induce further collisions, in this case, it replaces the target atom and fall into the vacancy site created by its movement. The other case for the occurrence of replacement collisions is in single element targets with large recoil cascades. Since the cascade propagation is not followed here, this type of collision will not occur.

\section{Total Displacements}

Total Displacements $=29056 /$ Ion

Total Vacancies $=29056 /$ Ion

Replacement Collisions $=0 /$ Ion

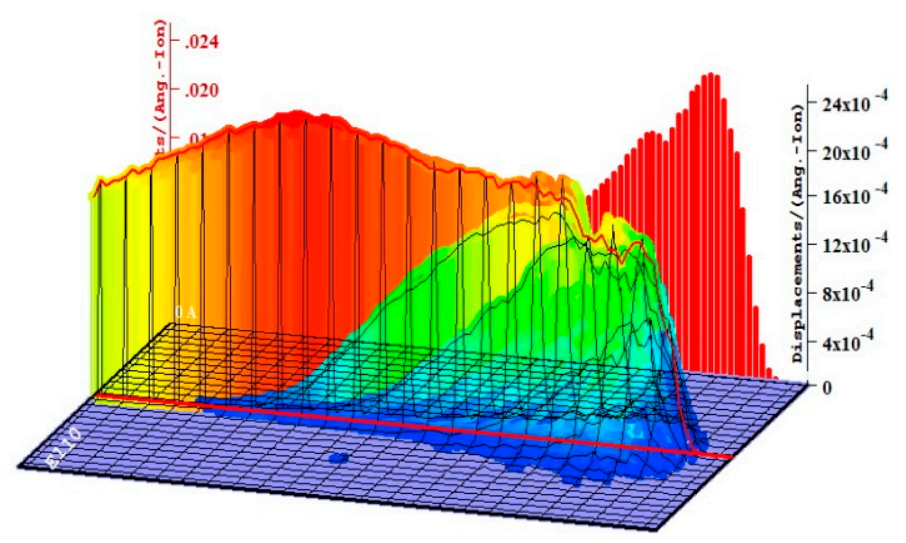

Plot Window goes from $0 \mathrm{~A}$ to $12 \mathrm{um}$; cell width $=1200 \mathrm{~A}$

Figure 8. Damage caused by $120 \mathrm{MeV}$ Ru in E110 alloy. 


\section{Total Displacements}

Total Displacements $=24298 /$ Ion

Total Vacancies $=24298 /$ Ion

Replacement Collisions $=0 /$ Ion

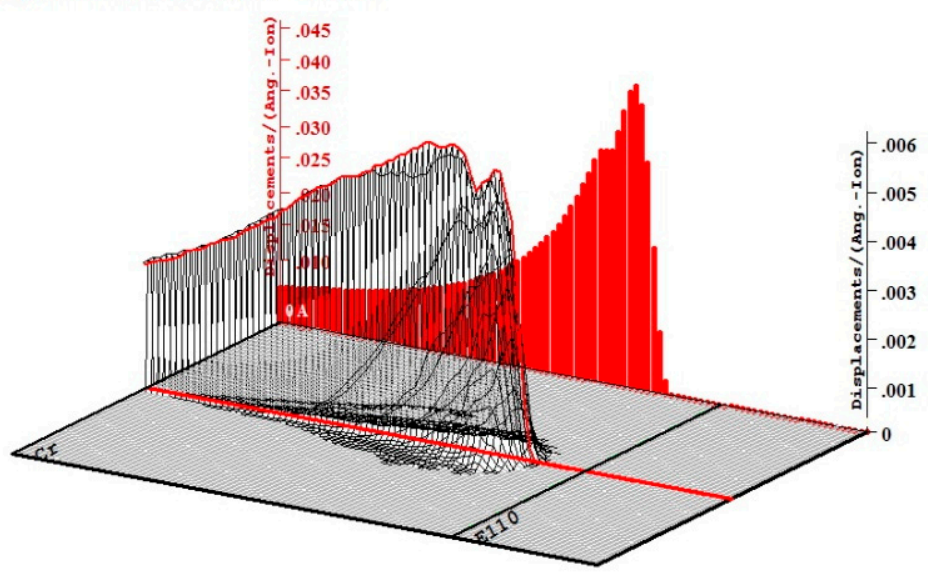

Plot Window goes from $0 \mathrm{~A}$ to $12 \mathrm{um}$ : cell width $=1200 \mathrm{~A}$

Figure 9. Damage caused by $120 \mathrm{MeV} R u$ in E110 alloy, coated with $9 \mu \mathrm{m}$ thin film of Cr.

The maximum anticipated recoil energy for molybdenum (Mo) produced during the fission of nuclear fuel is about $120 \mathrm{MeV}$. This high energetic particle is expected to induce a total damage in the cladding material (E110) 26,826 vacancies/ion. This damage extends to depths of more than $10 \mu \mathrm{m}$ inside the cladding material (Figure 10). Figure 11 shows the same damage calculations but for a coated cladding with a $9 \mu \mathrm{m}$ thin film of metallic chromium. In this case, calculations show that the fuel cladding material will remain intact as the energetic Mo will be stopped inside the $\mathrm{Cr}$ with a relatively shorter range, the displacement damage created will be less as well.

\section{Total Displacements}

Total Displacements $=26826 /$ Ion

Total Vacancies $=26826$ / Ion

Replacement Collisions $=0 /$ Ion

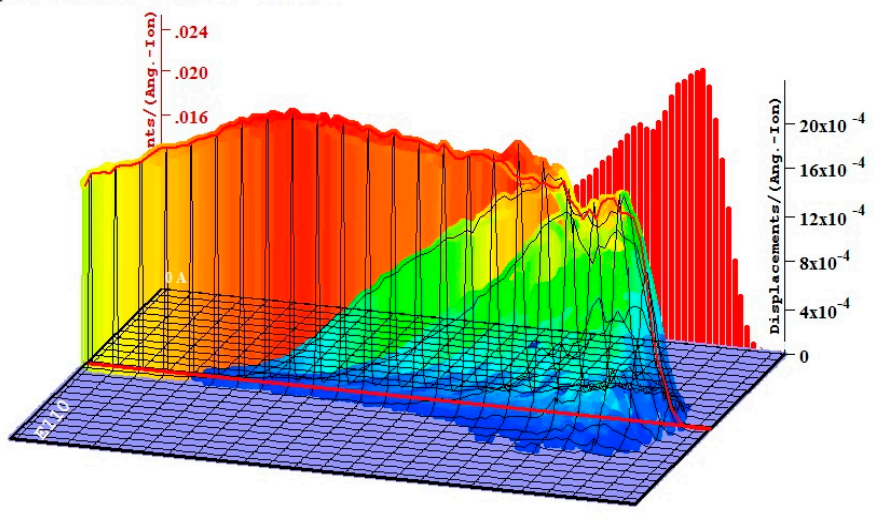

Plot Window goes from $0 \mathrm{~A}$ to $12 \mathrm{um}$; cell width $=1200 \mathrm{~A}$

Figure 10. Damage caused by $120 \mathrm{MeV}$ Mo in E110 alloy. 


\section{Total Displacements}

Total Displacements $=22509 /$ Ion

Total Vacancies $=22509 /$ Ion

Replacement Collisions $=0 /$ Ion

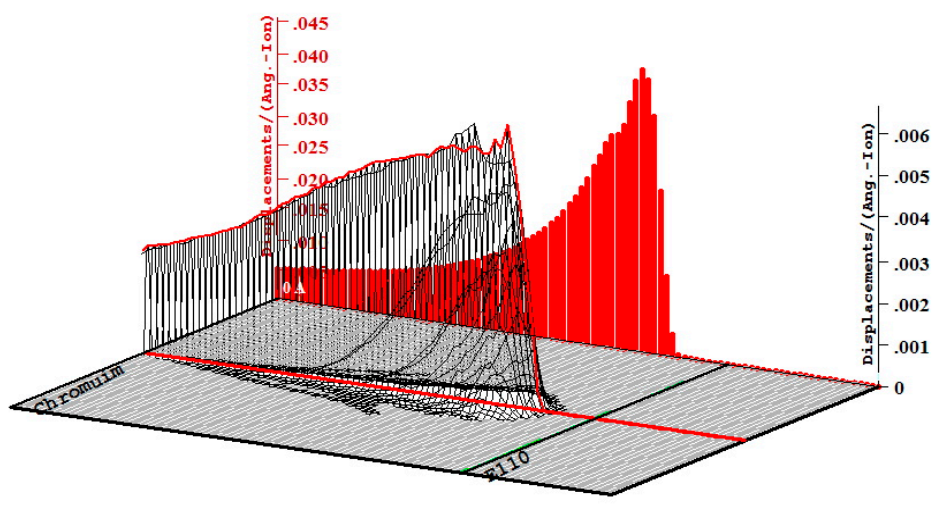

Plot Window goes from $0 \mathrm{~A}$ to $12 \mathrm{um}$; cell width $=1200 \mathrm{~A}$

Figure 11. Damage caused by $120 \mathrm{MeV}$ Mo in E110 alloy, coated with $9 \mu \mathrm{m}$ thin film of Cr.

The maximum damage that could be caused by rhodium (Rh) in E110 is shown in Figure 12. This is estimated to be $\sim 29,895$ vacancies/ion. It could be seen that this number is higher, when compared by the previous calculations, for the damage caused by Mo with the same maximum recoil energy which is estimated to be 26,826 vacancies/ion. This difference is justifiable, given the variations in atomic masses for the two FPs, the higher the mass, the more the displacement damage, created by the high energetic particle. Lighter energetic ions will induce lower displacements, however; it will travel longer inside the target until come to rest, and this means longer implantation depths. A thin film of $9 \mu \mathrm{m}$ in thickness will be able to contain this energetic FP (Figure 13) and eliminate its damaging effect on the nuclear fuel cladding material.

\section{Total Displacements}

Total Displacements $=29895 /$ Ion

Total Vacancies $=\mathbf{2 9 8 9 5} /$ Ion

Replacement Collisions $=0 /$ Ion

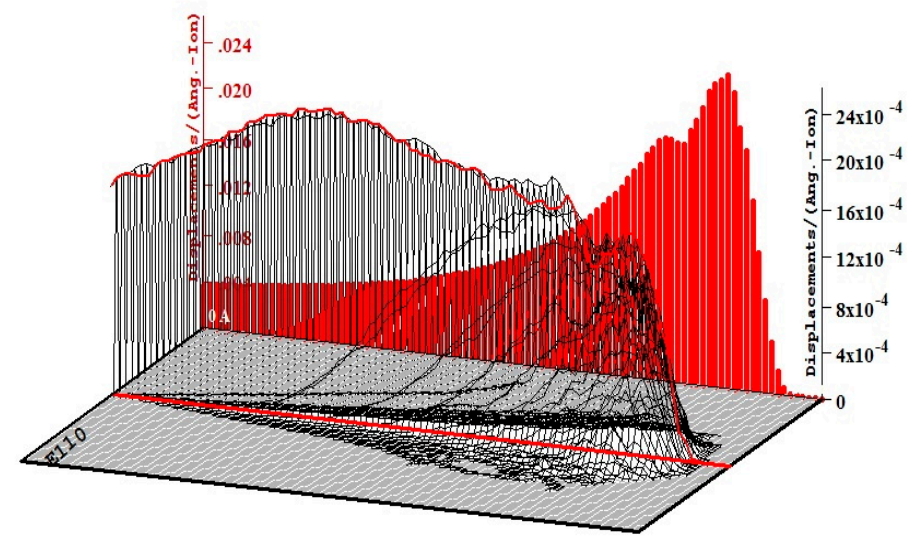

Plot Window goes from $0 \mathrm{~A}$ to $12 \mathrm{um}$; cell width $=1200 \mathrm{~A}$

Figure 12. Damage caused by $120 \mathrm{MeV}$ Rh in E110 alloy. 


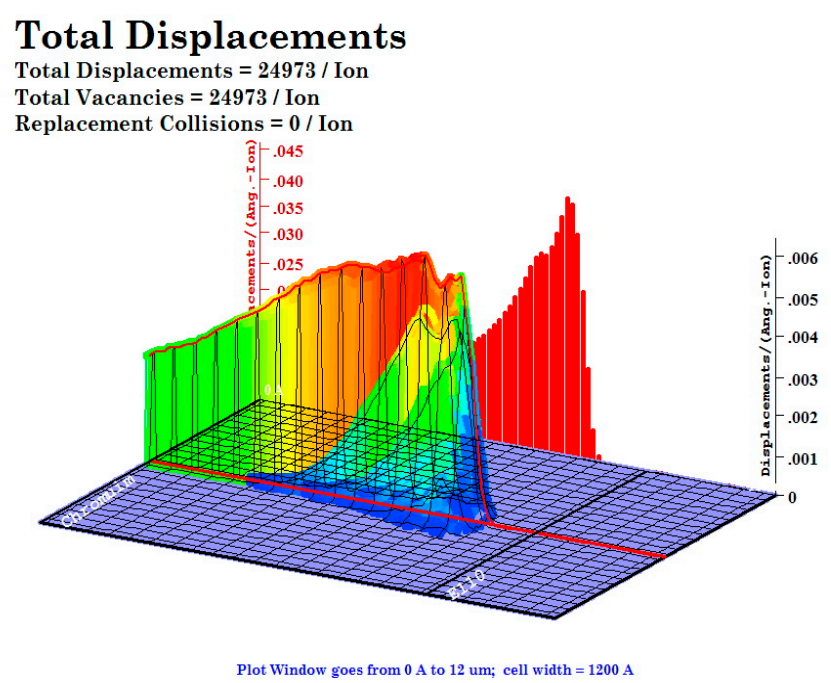

Figure 13. Damage caused by $120 \mathrm{MeV}$ Rh in E110 alloy, coated with $9 \mu \mathrm{m}$ thin film of Cr.

The calculated maximum damage induced by $120 \mathrm{MeV}$ palladium $(\mathrm{Pd})$ in the E110 alloy and the corresponding protective chromium coating thickness required is illustrated in Figures 14 and 15. Again, the calculations show that a thin $\mathrm{Cr}$ film $\sim 9 \mu \mathrm{m}$ will be capable enough to protect the fuel cladding from the damage induced by highly energetic Pd recoil, and contains this damage accordingly.

\section{Total Displacements \\ Total Displacements $=31339 /$ Ion}

Replacement Collisions $=0 /$ Ion
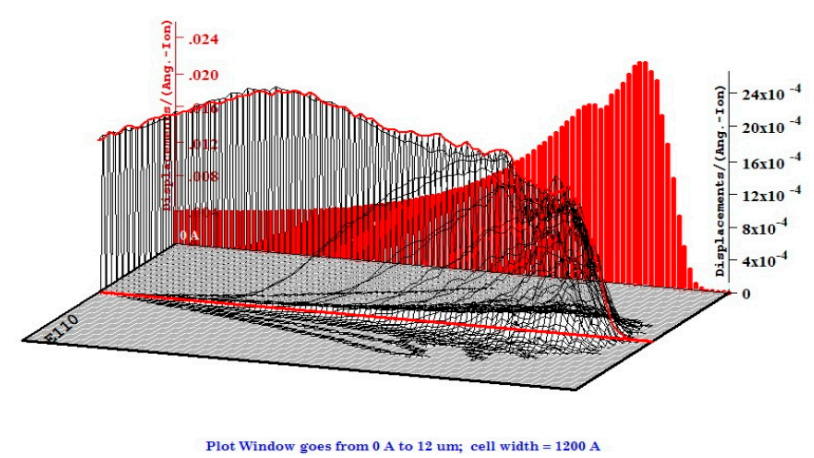

Figure 14. Damage caused by $120 \mathrm{MeV}$ Pd in E110 alloy.

\section{Total Displacements}

Total Displacements $=26060 /$ Ion

Total Vacancies $=26060 /$ Ion

Replacement Collisions $=0 /$ Ion

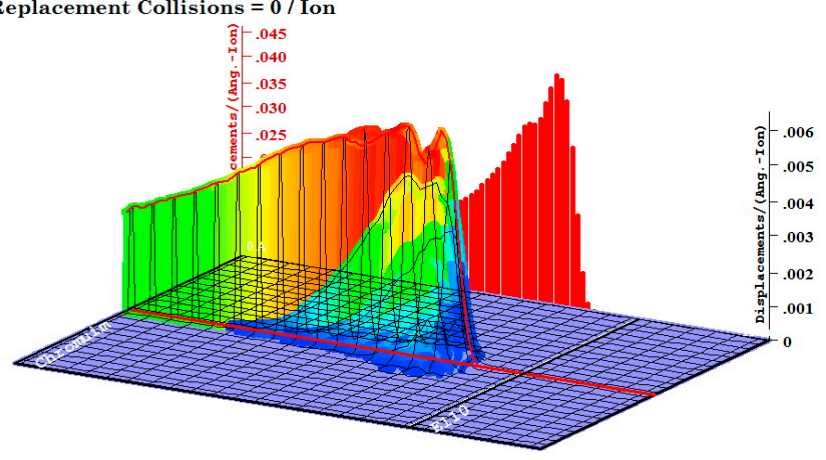

Plot Window goes from $0 \mathrm{~A}$ to $12 \mathrm{um}$; cell width $=1200 \mathrm{~A}$

Figure 15. Damage caused by $120 \mathrm{MeV}$ Pd in E110 alloy, coated with $9 \mu \mathrm{m}$ thin film of Cr. 
Figures 16-19 show the calculated damage, induced by the volatile species Iodine and Cesium, with/and without the application of a $\mathrm{Cr}$ film. These species are of particular interest in terms of their harmful impact on the zirconium based cladding materials, especially iodine, as it considered as a corrosive agent and a main contributor in SCC phenomenon. Calculations show that a thin chromium film of about $8 \mu \mathrm{m}$ will successively lead to the containment of the damage that would be arise in the fuel cladding inner wall as a result of the presence of these two important fission products (Figures 17 and 19). Thus, by applying this $8 \mu \mathrm{m}$ thin film on the inner surface of fuel cladding, the implantation of fission recoils inside the cladding will be prevented, and the hardening of inner-walls will be limited. Eventually; this will hinder, to a large extent, the appearance of cracks during reactor operation. This will result in limiting the presence of pathways to volatile fission species to migrate for longer depths inside the cladding and cause further corrosion and inner-surface degradation.

Total Displacements

Total Displacements $=40409 /$ Ion

Total Vacancies $=40409 /$ Ion

Replacement Collisions $=0 /$ Ion

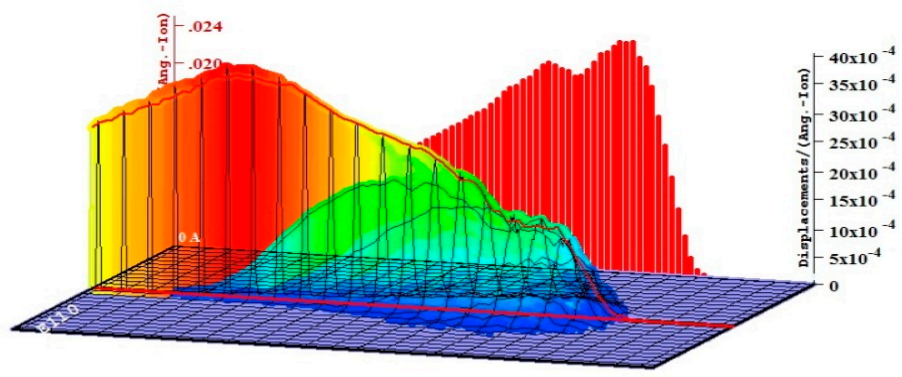

Plot Window goes from 0 A to 12 um; cell width $=1200 \mathrm{~A}$

Figure 16. Damage caused by $90 \mathrm{MeV}$ Iodine in E110 alloy.

Total Displacements

Total Displacements $=33502 /$ Ion

Total Vacancies $=33502 /$ Ion

Replacement Collisions $=0 /$ Ion

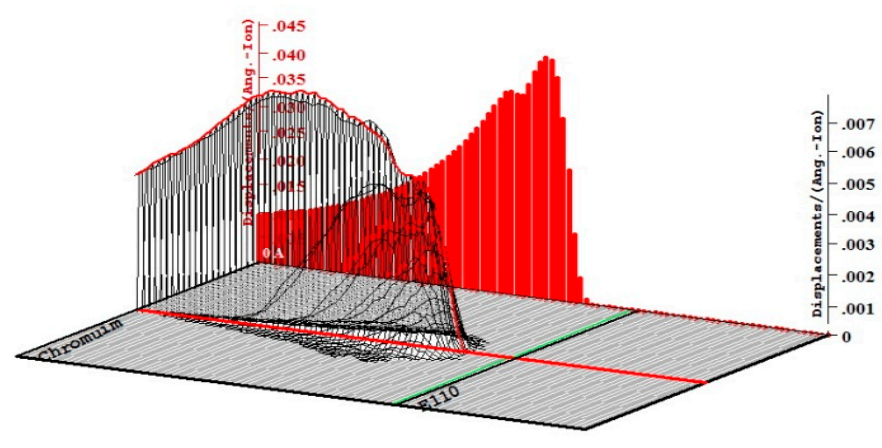

Plot Window goes from $0 \mathrm{~A}$ to $12 \mathrm{um}$; cell width $=1200 \mathrm{~A}$

Figure 17. Damage caused by $90 \mathrm{MeV}$ Iodine in E110 alloy, coated with $8 \mu \mathrm{m} \mathrm{Cr}$ thin film. 
Total Displacements

Total Displacements $=43736 /$ Ion

Total Vacancies $=43736 /$ Ion

Replacement Collisions $=0 /$ Ion

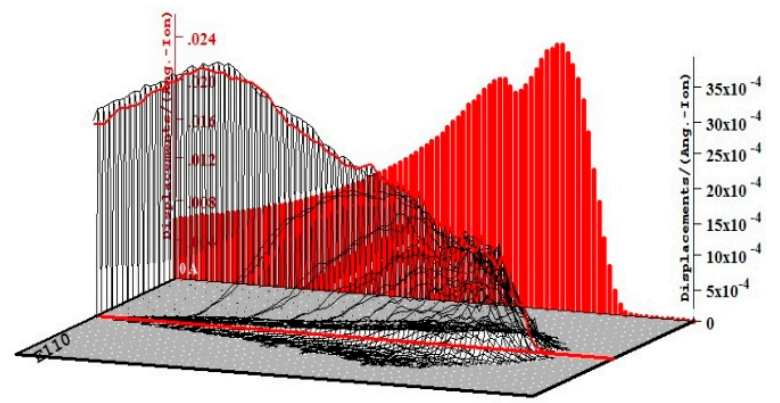

Plot Window goes from $0 \mathrm{~A}$ to $12 \mathrm{um}$; cell width $=1200 \mathrm{~A}$

Figure 18. Damage caused by $95 \mathrm{MeV}$ Cs in E110 alloy.

\section{Total Displacements}

Total Displacements $=36327 /$ Ion

Total Vacancies $=36327 /$ Ion

Replacement Collisions $=0 /$ Ion

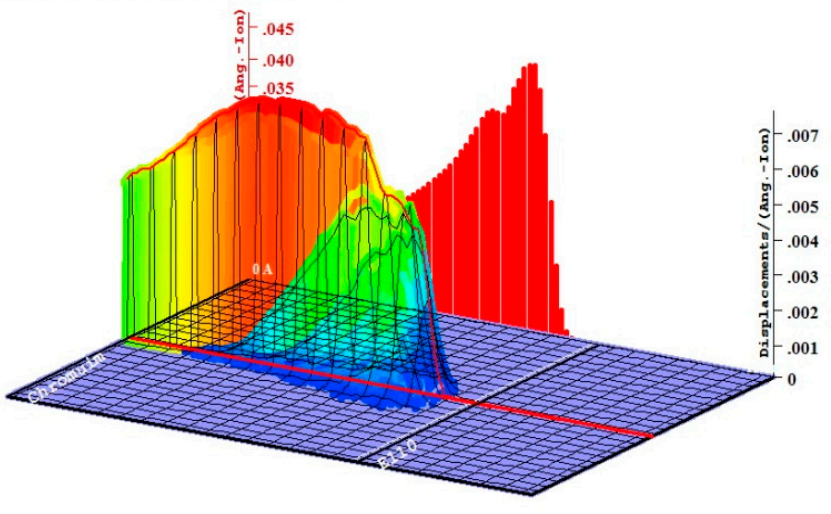

Plot Window goes from $0 \mathrm{~A}$ to 12 um; cell width $=1200 \mathrm{~A}$

Figure 19. Damage caused by $95 \mathrm{MeV}$ Cs in E110 alloy, coated with $8 \mu \mathrm{m} \mathrm{Cr}$ thin film.

An important observation from the above calculations is that, metallic chromium has an increased ability to stop (stopping power) the energetic fission products simulated in this study, as these particles have longer average paths inside the zirconium alloy compared by metallic chromium. A comparison is shown in Figure 20, while the $120 \mathrm{MeV}$ energetic Mo can travel inside the zirconium-based alloy for a depth of over $10 \mu \mathrm{m}$, it can be stopped inside $\mathrm{Cr}$ within a depth less than $8 \mu \mathrm{m}$. This may indicate the ability of chromium to withstand irradiation of energetic fission fragments for extended periods when compared to zirconium-based alloys, as the affected depth is much less in the former. This observation could also be closely linked to the remarks made on SCC phenomenon, in the sense that it does not affect pure metals as it does with alloys. Therefore, the classic approach to SCC prevention is based on the application of pure metal thin film on the inner side of the cladding tube [15] (zirconium liner in BWR and graphite in CANDU). 


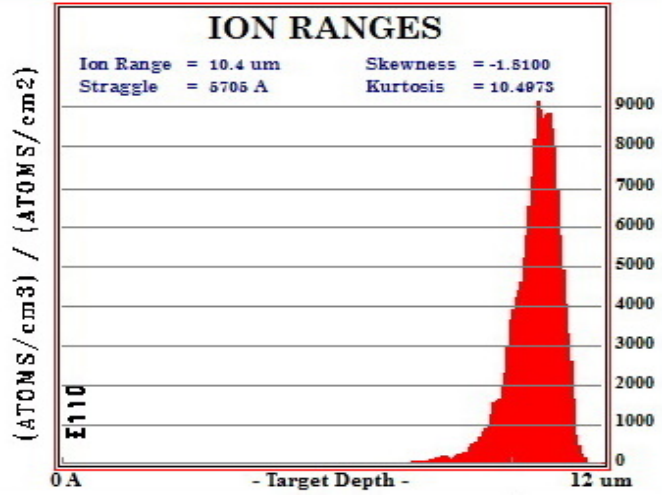

(a) Ion range for $120 \mathrm{MeV}$ Mo in E110 alloy

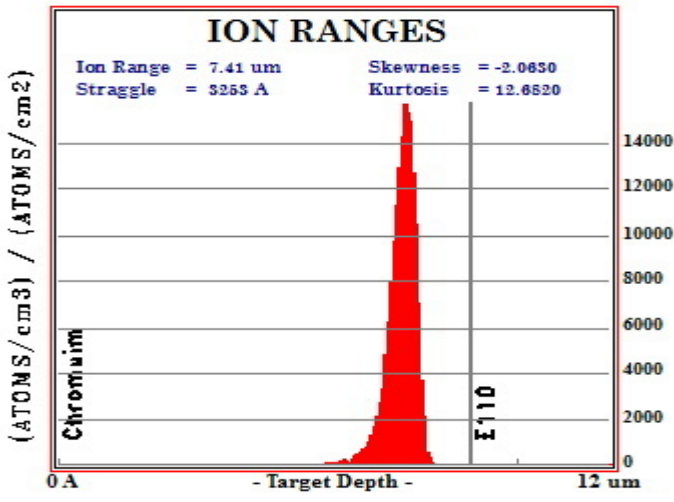

(b) Ion range for $120 \mathrm{MeV}$ Mo in E110 alloy, coated with $9 \mu \mathrm{m} \mathrm{Cr}$ thin film

Figure 20. Ion ranges for $120 \mathrm{MeV}$ Mo in: (a) Zirconium - based alloy, E110 (b) metallic Chromium.

\section{Conclusions}

The use of thin film coatings on the internal surface of nuclear fuel cladding was proposed within the context of ATF, to provide further enhancement against corrosion and secondary hydrogenation. The inner surface thin film is expected to provide protection for the cladding material, against the effects of fission fragments, produced during the fission process, overcoming the fuel, and migrating to fuel cladding internal surface. Protection against wide range of radiation induced phenomena, and cladding material degradation will be offered. TRIM calculations were performed to study the ranges for a selected group of FPs that are experimentally observed, and mostly known to be linked to cladding innerside degradation phenomena. The ranges were calculated inside the zirconium based alloy E110, to identify the depth that will be affected by these FPs, and evaluate the damage. As conservative approach, the maximum anticipated recoil energies for the studied group of FPs were used in the calculations. The expected damage caused by these products was also calculated. Based on this, a minimum thin chromium film of about $9 \mu \mathrm{m}$ in thickness is recommended. This film is expected to offer sufficient protection and contain the energetic recoils, migrating to the inner wall of fuel cladding and play major role in its degradation. Thereby, limiting the inner-surface degradation and providing further enhancement for the zirconium based fuel cladding during normal operation and accidental conditions. The calculations also showed that metallic chromium had more stopping power and less total induced displacement damage in comparison with the $\mathrm{Zr}$ - based alloy. It is worth mentioning that, the calculated minimum thickness of $\mathrm{Cr}$ is not expected to significantly affect the reactor reactivity and would probably results in less than a $1 \%$ decrease in fuel cycle length according to calculations made by Novak and Sevecek [21]. On the other hand, applying an inner surface thin film will provide protection for the fuel cladding against the internal corrosion and SCC, supporting the ability to increase fuel burnup during reactor operation as well as contributing to improved spent fuel management and waste minimization. However, the effects of this energetic FPs on metallic chromium thin film microstructure need to be thoroughly investigated and taken into account.

Author Contributions: Conceptualization, R.H.K.; methodology, R.H.K. and N.N.N.; software, R.H.K.; validation, R.H.K. and N.N.N.; formal analysis, R.H.K.; investigation, R.H.K.; resources, N.N.N.; data curation, R.H.K. and N.N.N.; writing—original draft preparation, R.H.K.; writingreview and editing, N.N.N. and V.N.K.; visualization, R.H.K.; supervision, N.N.N.; project administration, N.N.N. and V.N.K.; funding acquisition, N.N.N. and V.N.K. All authors have read and agreed to the published version of the manuscript.

Funding: This research was funded by Russian Science Foundation, research project No. 19-79-10116.

Institutional Review Board Statement: Not applicable. 
Informed Consent Statement: Not applicable.

Data Availability Statement: The data presented in this study are available on request from the corresponding author.

Acknowledgments: This research was supported by Tomsk Polytechnic University CE Program.

Conflicts of Interest: The authors declare no conflict of interest.

\section{References}

1. Chen, H.; Wang, X.; Zhang, R. Application and Development Progress of Cr-Based Surface Coatings in Nuclear Fuel Element: I. Selection, Preparation, and Characteristics of Coating Materials. Coatings 2020, 10, 808. [CrossRef]

2. Tang, C.; Stueber, M.; Seifert, H.J.; Steinbrueck, M. Protective coatings on zirconium-based alloys as accident-tolerant fuel (ATF) claddings. Corros. Rev. 2017, 35, 141-165. [CrossRef]

3. Brachet, J.C.; Idarraga; Trujillo, I.; Flem, M.L.; Saux, M.L.; Vandenberghe, V.; Urvoy, S.; Rouesne, E. Early studies on Cr-coated Zircaloy-4 as enhanced accident tolerant nuclear fuel claddings for light water reactors. J. Nucl. Mater. 2019, 517, $268-285$. [CrossRef]

4. Brachet, J.C.; Le Saux, M.; Le Flem, M.; Urvoy, S. On-Going Studies at CEA on Chromium Coated Zirconium Based Nuclear Fuel Claddings for Enhanced Accident Tolerant LWRs Fuel. In Proceedings of the Top Fuel; Zurich, Switzerland; Available online: https:/ / www.researchgate.net/publication/283446965 (accessed on 12 June 2021).

5. Lach, T.G.; Edwards, D.J.; Buck, E.C.; McNamara, B.K.; Schwantes, J.M.; Clark, R. Fission recoil-induced microstructural evolution of the fuel-cladding interface [FCI] in high burnup BWR fuel. J. Nucl. Mater. 2019, 521, 120-125. [CrossRef]

6. Schuster, I.; Lemaignan, C. Embrittlement, induced by fission recoils, of the inner surface of PWR fuel cladding-A simulation using heavy ions. J. Nucl. Mater. 1988, 151, 108-111. [CrossRef]

7. Nakatsuka, M.; Nomata, T.; Umehara, H. Development of the Ultra-microhardness Technique for Post Irradiation Examination of Fuel Cladding Tubes. J. Nucl. Sci. Technol. 1998, 35, 344-352. [CrossRef]

8. Michau, A.; Maury, F.; Schuster, F.; Lomello, F.; Boichot, R.; Pons, M.; Brachet5, J.-C.; Monsifrot, E. Inner-side coatings for advanced fuel claddings processed by DLI- MOCVD. In Proceedings of the 2017 Water Reactor Fuel Performance Meeting, Jeju Island, Korea, 10-14 September 2017.

9. Edsinger, K.; Murty, K.L. LWR pellet-cladding interactions: Materials solutions to SCC. JOM 2001, 53, 9-13. [CrossRef]

10. Michau, A.; Gazal, Y.; Maury, F.; Boichot, R.; Duguet, T.; Pons, M.; Brachet, J.-C.; Monsifrot, E.; Schuster, F.; Maskrot, H. Inner surface protection of nuclear fuel cladding, towards a full-length treatment by DLI-MOCVD, an optimized coating process. In Proceedings of the Top Fuel 2018, Prague, Czech Republic, 30 September-4 October 2018.

11. Michau, A.; Gazal, Y.; Addou, F.; Maury, F.; Duguet, T.; Boichot, R.; Pons, M.; Monsifrot, E.; Maskrot, H.; Schuster, F. Scale up of a DLI-MOCVD process for the internal treatment of a batch of 16 nuclear fuel cladding segments with a CrCx protective coating. Surf. Coat. Technol. 2019, 375, 894-902. [CrossRef]

12. Rymzhanov, R.A.; Saifulin, M.M.; Akilbekov, A. Numerical estimation of fission fragments flux on surface of fuel cladding. In Proceedings of the 12th International Conference Interaction of Radiation with Solids, Minsk, Belarus, 19-22 September 2017.

13. Ziegler, J.F. SRIM-2003. Nucl. Instrum. Methods Phys. Res. B 2004, 219-220, 1027-1036. [CrossRef]

14. Clark, R.A.; Conroy, M.A.; Lach, T.G.; Buck, E.C.; Pellegrini, K.L.; Mcnamara, B.K.; Schwantes, J.M. Distribution of metallic fi ssion-product particles in the cladding liner of spent nuclear fuel. NPJ Mater. Degrad. 2020, 4, 1-9.

15. Sidky, P. Iodine stress corrosion cracking of Zircaloy reactor cladding: Iodine chemistry (a review). J. Nucl. Mater. 1998, 256, 1-17. [CrossRef]

16. Ziegler, J.F.; Biersack, J.P.; Ziegler, M.D. SRIM-The Stopping and Range of Ions in Matter; SRIM Co.: Boston, MA, USA, 2008; ISBN 0-9654207-1-X.

17. Stoller, R.; Toloczko, M.; Was, G.; Certain, A.; Dwaraknath, S.; Garner, F. On the use of SRIM for computing radiation damage exposure. Nucl. Instrum. Methods Phys. Res. B 2013, 310, 75-80. [CrossRef]

18. Kinchin, G.H.; Pease, R.S. The Displacement of Atoms in Solids by Radiation. Rep. Prog. Phys. 1955, 18, 1-51. [CrossRef]

19. Hirabayashi, T.; Sato, T.; Sagawa, C.; Masaki, N.; Saeki, M.; Adachi, T. Distributions of radionuclides on and in spent nuclear fuel claddings of pressurized water reactors. J. Nucl. Mater. 1990, 174, 45-52. [CrossRef]

20. Ciszak, C.; Mermoux, M.; Miro, S.; Gutierrez, G.; Lepretre, F.; Popa, I.; Hanifi, K.; Zacharie-Aubrun, I.; Fayette, L.; Chevalier, S. Micro-Raman analysis of the fuel-cladding interface in a high burnup PWR fuel rod. J. Nucl. Mater. 2017, 495, 392-404. [CrossRef]

21. Novák, O.; Sevecek, M. Neutronic Analysis of the Candidate Multi-Layer Cladding Materials with Enhanced Accident Tolerance for Wwer Reactors. Acta Polytechnica CTU Proc. 2018, 14, 27-33. [CrossRef] 